\title{
Monoclonal Antibody against an Amniotic Protein Carrying ABH Blood Group Epitopes and Its Forensic Application
}

\author{
Mikiko Nagae, Yasuhiro Aoki, Masayuki Nata, Masaki \\ HashiYada and KaORU Sagisaka \\ Department of Forensic Medicine, Tohoku University School \\ of Medicine, Sendai 980-77
}

\begin{abstract}
Nagae, M., Aoki, Y., Nata, M., Hashiyada, M. and Sagisaka, K. Monoclonal Antibody against an Amniotic Protein Carrying ABH Blood Group Epitopes and Its Forensic Application. Tohoku J. Exp. Med., 1995, 177 (4), 353-364 A mouse monoclonal antibody against an amniotic protein carrying $\mathrm{ABH}$ antigenic epitopes was established. BALB/c mice were immunized by an amniotic protein of molecular weight over $200 \mathrm{kDa}$, which had proved to be the carrier protein of ABH blood group epitopes by analysis with SDS-PAGE and immunoblotting. The antibody, ASP-1, was directed to the amniotic carrier protein without affecting the $\mathrm{ABH}$ blood group antigenicity, and did not cross-react with other body fluids which included blood, saliva, semen, urine or vaginal secretion. The immunoglobulin class of ASP-1 was IgG1 with a titer of $1: 1,600$. ASP- 1 was used to detect the ABH blood group of amniotic fluid by the sandwich ELISA in which wells of plates were coated with ASP-1, and the ABH blood group of the captured protein was detected with mouse IgM anti-A and -B antibodies and enzyme conjugated anti-mouse IgM. The sandwich ELISA could successfully detect the blood group of amniotic fluid in mixed body fluids. —— amniotic fluid; ABH blood group; ELISA; monoclonal antibody; forensic serology
\end{abstract}

The identification of pregnancy from evidence found at a scene may give information for criminal investigations in cases of neonaticide. As a hallmark of the delivery, some pregnancy associated proteins have been studied (Sagisaka and Takahashi 1975), whereas attempts to detect the amniotic fluid from the scene are less common. It has been confirmed that the $\mathrm{ABH}$ blood group antigen in amniotic fluid are derived from the fetus in and after mid-trimester (Ogita et al. 1975). The amniotic protein carrying the $\mathrm{ABH}$ blood group epitopes, however, has not been identified. The evidence originating from amniotic fluid should co-exist with that of other body fluids such as blood, urine and vaginal secretions with few exceptions. Thus, ABO blood grouping of each constituent of a mixed body fluid should be mandatory for the scene investigation in cases of neonaticide. In this study, we analysed an amniotic protein carrying the $\mathrm{ABH}$ blood group antigens and established a monoclonal antibody against it. The potential avail-

Received June 12, 1995; revision accepted for publication October 21, 1995. 
ability of this antibody in discriminative $\mathrm{ABH}$ blood grouping is described.

\section{Materials and Methods}

Specimens. Amniotic fluid samples, peripheral blood samples were obtained from women in the 16th week of gestation in the Department of Obstetrics and Gynecology, Tohoku University School of Medicine. Cord blood samples were also collected from neonates in the department. The amniotic fluids were centrifuged at $500 \mathrm{rpm}$ for $10 \mathrm{~min}$ to remove cellular components. ABO blood grouping of the supernatant was performed using ELISA. To prepare the immunogen, group $\mathrm{A}$ and $\mathrm{O}$ amniotic fluids were fractionated using FPLC (Superose 12, Pharmacia, Uppsala, Sweden) and the blood group activity of each fraction of group A amniotic fluid was assayed by ELISA. The fraction of group $\mathrm{O}$ amniotic fluid whose molecular weight was comparable to that of group A amniotic fluid with the highest group A activity was collected as immunogen. The samples of group A and B semen and saliva, and group B blood, urine and vaginal secretions were also prepared.

Antibodies. Mouse monoclonal IgM anti-A and anti-B were prepared in our laboratory. Commercial monoclonal IgM anti-A and anti-B were purchased from Bioscot (Edinburgh, UK). Peroxidase conjugated goat anti-mouse IgG + IgM and alkaline phosphatase conjugated goat anti-mouse IgG and IgM were obtained from Tago (Burlingame, CA, USA).

$S D S-P A G E$ and immunoblotting. The identification of amniotic protein carrying the $\mathrm{ABH}$ blood group antigens was performed with SDS-PAGE and immunoblotting. The gels containing $7.5 \%$ polyacrylamide and $0.1 \%$ SDS were prepared as described by Laemmli (1970). Gradient polyacrylamide gels (3$10 \%$ ) containing $0.1 \%$ SDS were also used to examine the antigenicity of amniotic proteins against the established antibody. Immunoblotting was performed using a PVDF membrane (Immobilon; Millipore, Bedford, MA, USA) for passive transfer of proteins. The membrane was incubated with the corresponding antibodies and peroxidase conjugated antibody with 4-chloro-1-naphthol as the substrate for color development. Proteins were also visualized with Coomassie brilliant blue $(\mathrm{CBB})$ staining and the periodic acid Schiff (PAS) reaction.

Production of monoclonal antibody against amniotic fluid. BALB/c mice were immunized intraperitoneally with $10 \mu \mathrm{g}$ /injection of the immunogen. The immunogen was diluted with saline and emulsified with an equal volume of Freund's complete adjuvant (Nakarai, Kyoto). The animals received two more injections of the same amount of immunogen emulsified with incomplete adjuvant at 10-day intervals. Three days before fusion, the host animal received an intravenous boost of $10 \mu \mathrm{g}$ of the diluted immunogen. The splenocytes of the host animal were fused with Sp2/0-Ag14 myeloma cells. After consecutive limited dilution clonings and antibody screening of culture supernatant with ELISA, the established clone (ASP-1) was expanded and incubated in BALB/c 
mice (Köhler and Milstein 1975). A mouse monoclonal antibody isotyping kit (Amersham, Backinghamshire, UK) was used to determine the immunoglobulin class of monoclonal antibodies.

ELISA with solid phase antigen. Polystyrene plates (Falcon Pro-bind assay plate, Becton Dickinson, Lincoln Park, NJ, USA) were coated with either amniotic fluid or other body fluids in $50 \mu 1$ of $50 \mathrm{mM}$ carbonate buffer, $\mathrm{pH} 9.6$. After washing with PBS containing $0.1 \%$ Tween 20 (Tween-PBS), free binding sites were blocked with $100 \mu \mathrm{l}$ of $2 \%$ skimmed milk in PBS for 20 min at room temperature. Before adding $100 \mu \mathrm{l}$ of diluted anti-amniotic protein, anti-A or anti-B, the plates were washed with Tween-PBS. The plates were then incubated for $1 \mathrm{hr}$ at $37^{\circ} \mathrm{C}$. After washing, the wells were incubated for $1 \mathrm{hr}$ at $37^{\circ} \mathrm{C}$ with alkaline phosphatase conjugated antibody. Consequently, the plates were developed with nitrophenolphosphate and the absorbance at $410 \mathrm{~nm}$ was measured using an ELISA plate reader (Corona, MTP-12A; Katsuta).

Blood grouping with the double-antibody sandwich ELISA. The plates were coated with $50 \mu$ l of ASP-1 (1:1,000), blocked and washed as described above. Aliquots of $50 \mu \mathrm{l}$ of the amniotic fluid or other body fluids diluted with PBS were added and incubated for $1 \mathrm{hr}$ at $37^{\circ} \mathrm{C}$. The plates were then incubated in sequence with anti-A or -B antibody and alkaline phosphatase conjugated antiIgM followed by color development with nitrophenolphosphate.

Immunohistochemical reactivity of human placenta and fetal or neonatal organs against ASP-1. The human placenta tissues were obtained from women of full term delivery in the Department of Obstetrics and Gynecology, Tohoku University School of Medicine. The lung, liver and kidney of the fetus and neonate were collected from the cadavers following autopsy in our department. Formalin-fixed, paraffin-embedded sections were incubated with ASP-1 (1:50) for $10 \mathrm{~min}$ at room temperature. The immunoreactivity was visualized with the avidin-biotin-peroxidase complex method (Hsu et al. 1981).

Detection of blood group antigens of the amniotic fluid in mixed body fluid samples. Mixtures of body fluids were made with blood group A amniotic fluid and group B hemolysate, urine, vaginal secretion, semen or saliva. The content of amniotic fluid in each mixed body fluid sample was adjusted to $1 \%, 10 \%$, $16.7 \%, 25 \%, 33.3 \%$ or $50 \%$. In the ELISA with solid phase antigen, the assay plates were coated with the mixed body fluid, and anti-A and anti-B antibodies were used as the primary antibodies. In the sandwich method, mixed body fluid samples were added to the plates coated with ASP-1.

\section{RESUlts}

Molecular weight of the amniotic protein carrying the ABH blood group antigens. The $\mathrm{ABH}$ blood group of the amniotic fluid was consistent with the result of blood grouping of the cord blood of the corresponding neonates. Immunodetection of group A activity in the group A amniotic fluid is shown in Fig. 1. In 


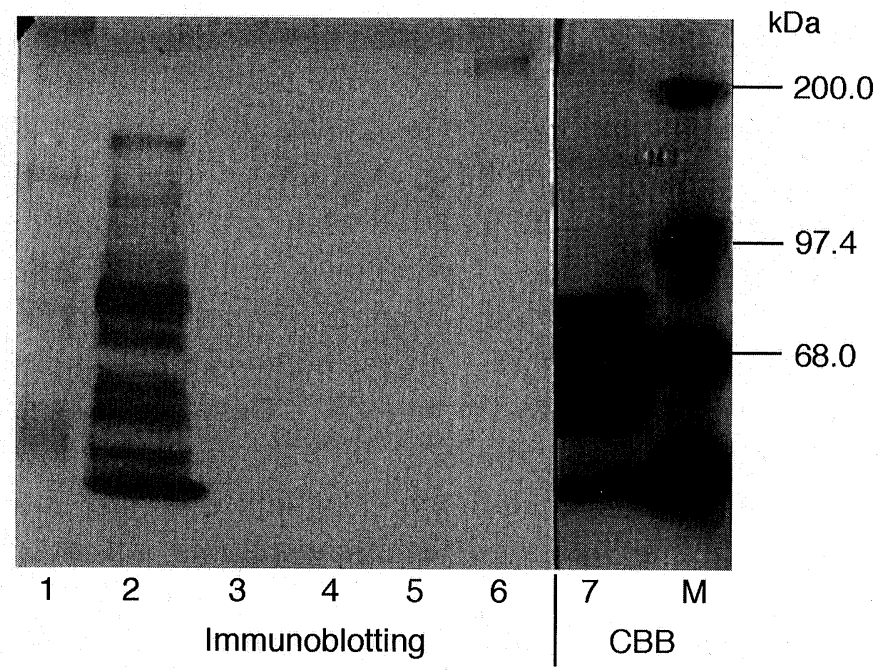

Fig. 1. Identification of proteins carrying group A antigens by SDS-PAGE and immunoblotting. Lane 1: group A saliva, 2: group A semen, 3-6: amniotic fluids of group $\mathrm{AB}, \mathrm{O}, \mathrm{B}, \mathrm{A}$, respectively. 7: group $\mathrm{A}$ amniotic fluid stained with CBB stain. M: molecular weight marker. Single immunoreactive band appeared at over $200 \mathrm{kDa}$ range in group $\mathrm{A}$ amniotic fluid. The corresponding band was faintly stained in group $A B$ amniotic fluid.

group A amniotic fluid, an immunoreactive band appeared in the range greater than $200 \mathrm{kDa}$. The corresponding band was faintly stained with CBB stain. This immunoreactive band was barely detected in group $\mathrm{AB}$ amniotic fluid, but not in group B or group $\mathrm{O}$ samples. A few bands of blood group activity were observed in group A saliva and semen, but their molecular weights were not identical with that of the amniotic fluid.

Gel filtration of group $A$ amniotic fluid. Fig. 2 shows a gel filtration profile of group A amniotic fluid with absorbance at $280 \mathrm{~nm}$ and blood group activity. In addition to 2 distinct peaks with high protein concentration, a few small peaks were also recognized. Group A activity was prominent in fractions corresponding to a small peak immediately left of the first main peak. The protein in the fractions was consistent with the high molecular weight protein detected by immunoblotting. A similar gel filtration profile was obtained with group $\mathrm{O}$ amniotic fluid.

Antibody characterization. The immunoglobulin class of ASP-1 was found to be IgG1. When the assay plates were coated with a 10-fold diluted pooled amniotic fluid, a clear positive reactions was shown using ASP-1 diluted up to 1 : 1,600 as the primary antibody. On the other hand, 1,000 fold diluted ASP-1 could detect the antigen in the pooled amniotic fluid diluted up to $1: 1,024$. The ELISA demonstrated that human semen, saliva, tear, urine and vaginal secretions 


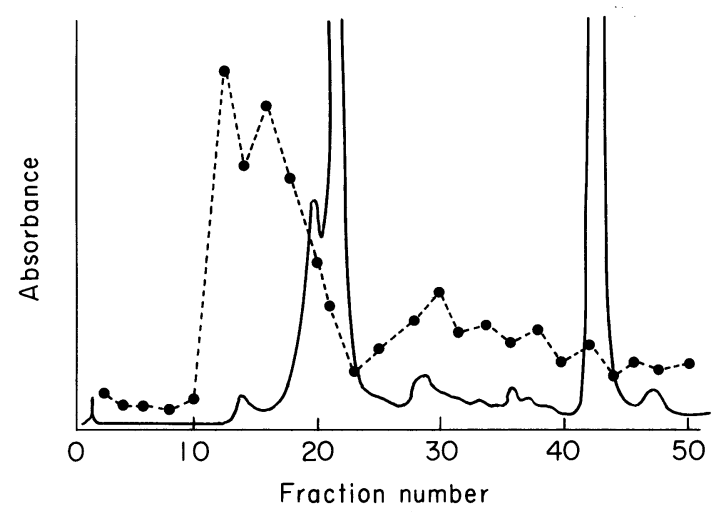

Fig. 2. Gel filtration profile (-) and group A activity (•- $\bullet$ ) of amniotic fluid. Group A activity was prominent in fraction No. 12-16. Gel, Superose 12; column size, $1 \times 30 \mathrm{~cm}$; eluent, PBS; flow rate, $0.5 \mathrm{ml} / \mathrm{min}$; sample applied, $0.2 \mathrm{ml}$; fraction size, $0.5 \mathrm{ml}$.

did not cross-react with 100-fold diluted ASP-1 (Fig. 3).

Immunodetection of the amniotic proteins reacting to ASP-1 is shown in Fig. 4. In group A and B amniotic fluid, a single immunoreactive band appeared in a position greater than $200 \mathrm{kDa}$. The corresponding band was faintly stained with CBB stain, but not with PAS reaction. Both staining methods showed a distinct band in the range $68 \mathrm{kDa}$.

Out of 93 amniotic fluid specimens collected, 92 gave positive reactions for ASP-1 with ELISA (Fig. 5). However, some diversity in the immunoreactivity, which had no correlation with protein concentration $(r=-0.014)$, was demonstrated. One specimen showed no antigenicity against ASP-1 (sample 3). The immunoreactivity against ASP-1 moderately correlated with the intensity of group

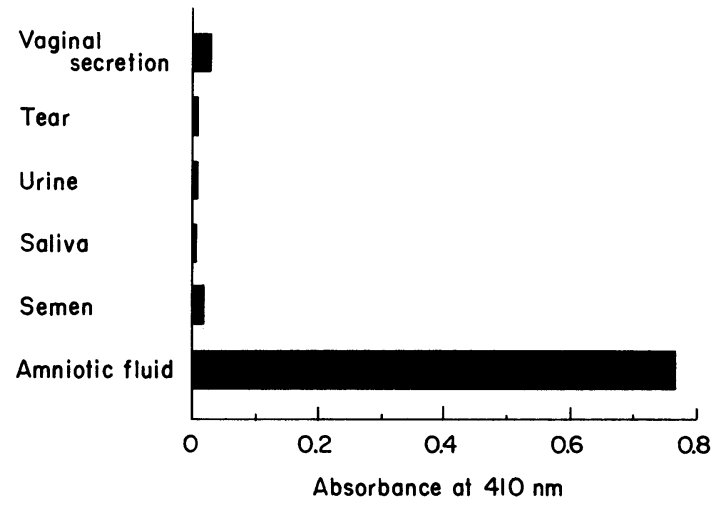

Fig. 3. Tissue specificity of ASP-1 analyzed with ELISA. Human semen, saliva, tear, urine and vaginal secretion did not cross-react with 100 -fold diluted ASP-1. 


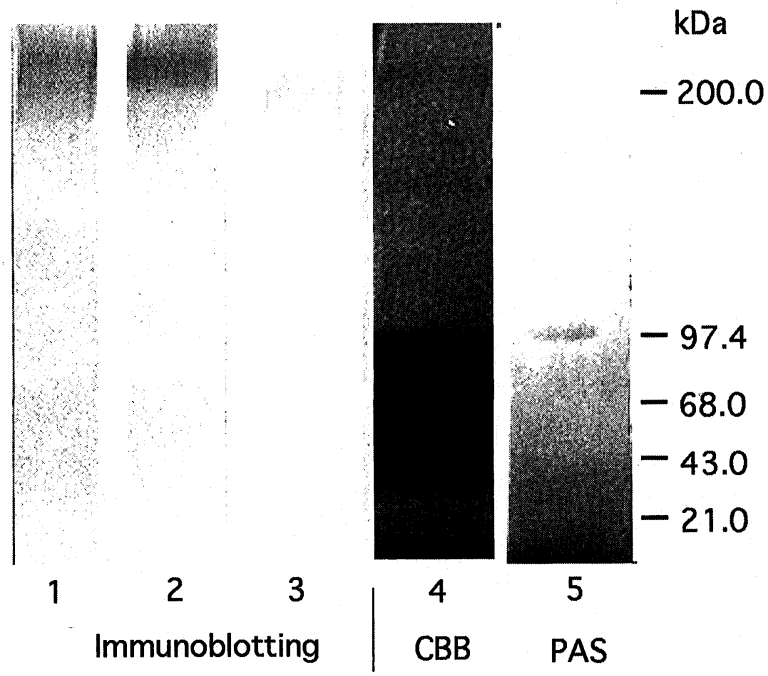

Fig. 4. Identification of amniotic protein defined by ASP-1. Amniotic proteins were separated with $3-10 \%$ gradient polyacrylamide gels containing $0.1 \%$ SDS, and transferred to PVDF membrane: The blot was stained with ASP-1. Lane 1: group A amniotic fluid, 2: group B amniotic fluid, 3: group A semen, 4, 5: group A amniotic fluid stained with $\mathrm{CBB}$ and PAS method, respectively. A single immunoreactive band appeared at over $200 \mathrm{kDa}$ range in lanes 1 and 2. The corresponding band was faintly stained with CBB stain, but not with PAS reaction.

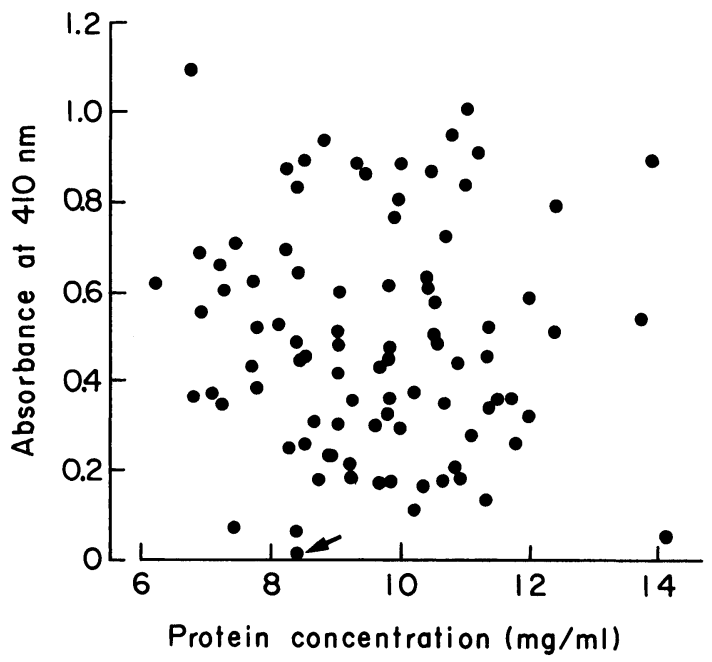

Fig. 5. Individual differences of antigenicity against ASP-1. Ninety three amniotic fluid specimens (dots) were examined. Diversity in the immunoreactivity had no correlation with protein concentration $(r=-0.014)$. One specimen (sample 3; arrowed) showed no antigenicity against ASP-1. 


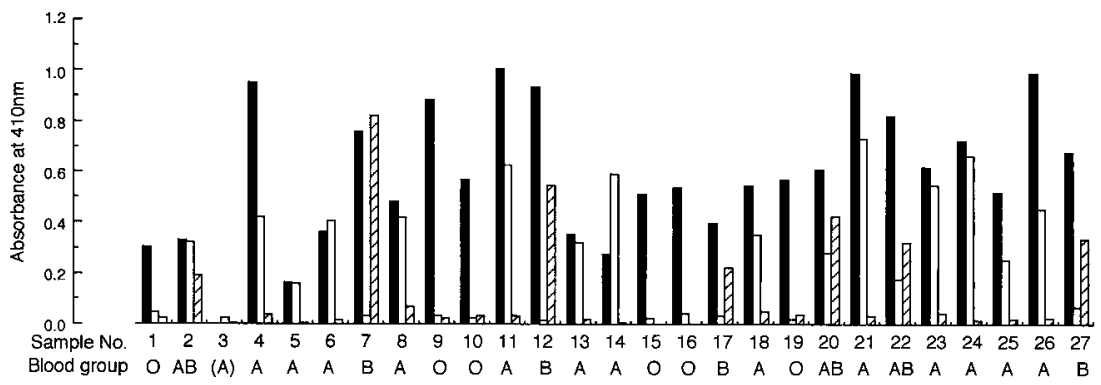

Fig. 6. Blood grouping of amniotic fluids using double antibody sandwich ELISA. Anti-A (white columns), and anti-B (hatched columns) were used as the second antibodies. Black columns show the results of ELISA using ASP-1 as primary antibody. All but one (sample 3) were typed successfully.

A $(n=16, \mathrm{r}=0.45)$ and group $\mathrm{B}(n=8, \mathrm{r}=0.67)$ antigenicity. Blood grouping of 27 specimens was performed using the sandwich ELISA, and all specimens except for sample 3 were typed successfully (Fig.6). Seminal proteins carrying blood group antigens could not be captured by ASP-1.

Immunohistochemistry. In the placenta, the cytoplasm of intermediate trophoblast was specifically stained with ASP-1 (Fig. 7a). The fetal and neonatal tissues showed no immunoreactivity against ASP-1, although the alveolar spaces were occasionally stained (Fig. 7b).

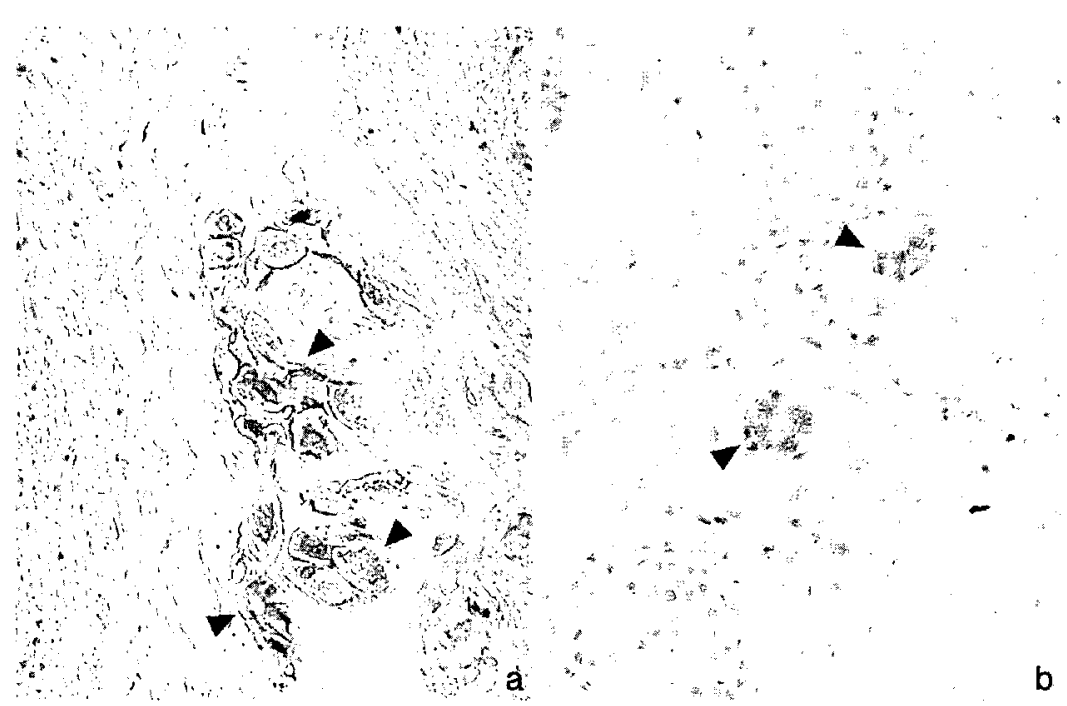

Fig. 7. Immunohistochemistry of the term placenta (a) and neonatal lung (b) stained with ASP-1. The cytoplasm of intermediate trophoblast (a, arrowheads) was positively stained. The alveolar spaces of the neonatal lung (b, arrowheads) were occasionally stained, no cellular components, however, were defined by ASP-1. a: $\times 240$, b: $\times 48$. 

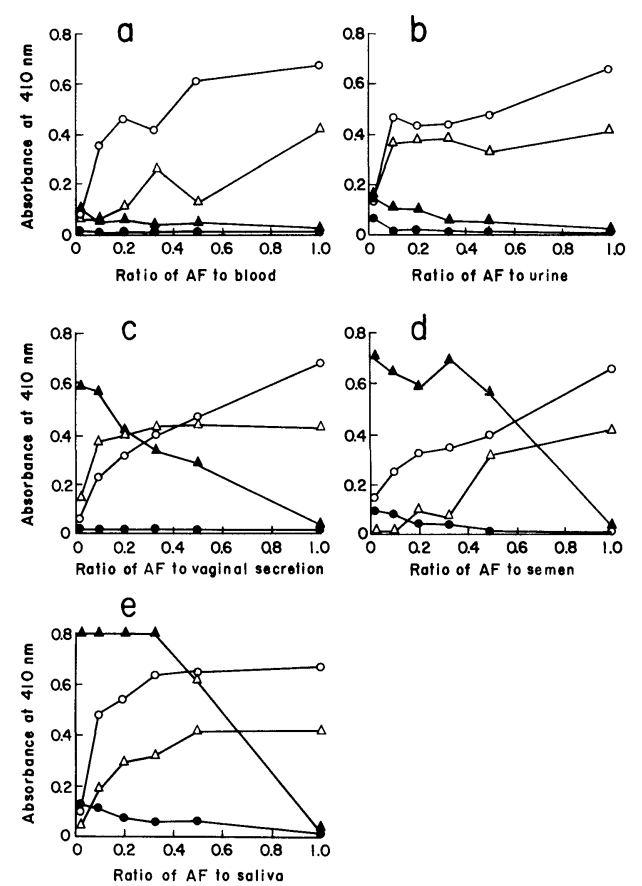

Fig. 8. ABH blood grouping of mixed fluids by ELISA with solid phase antigen and the sandwich ELISA; a: group A amniotic fluid (AF) and group B blood, b: group $\mathrm{A} A \mathrm{AF}$ and group $\mathrm{B}$ urine, c; group $\mathrm{A}$ AF and group $\mathrm{B}$ vaginal secretion, d: group A AF and group B semen, e: group A AF and group B saliva. $\square$ ELISA with solid phase antigen and anti-A; anti-B; $\bigcirc$ the sandwich ELISA with anti-A; $\bullet$ with anti-B. Employing the sandwich ELISA, exclusive detection of A antigen of AF was successful from the mixed body fluids containing $25 \%$ (ratio of $\mathrm{AF}$ to other body fluid is $33.3 \%$ ) or more $\mathrm{AF}$.

Detection of blood group antigens of the amniotic fluid in mixed body fluid samples. The ELISA with solid phase antigen failed to detect any blood group antigens at any ratios of mixtures of the amniotic fluid and hemolysate, whereas group A antigen of the amniotic fluid was selectively detected from all samples of the amniotic fluid and urine mixture. Both $\mathrm{A}$ and $\mathrm{B}$ antigens were detected in most samples of mixtures of the amniotic fluid and vaginal secretion. With the sandwich ELISA, group A antigen of the amniotic fluid was detectable from the mixed body fluids containing $10 \%$ or more amniotic fluid. Group B antigen of the hemolysate, urine, or vaginal secretion could not be detected in any samples (Fig. 8a-c).

The ELISA with solid phase antigen could not always detect A antigen of the amniotic fluid contaminated with group B semen or saliva, especially in the mixed fluid samples with high semen or saliva content. With the sandwich ELISA, non-specific adsorption of $\mathrm{B}$ antigen was occasionally observed in cases of a mixed 
body fluid containing $10 \%$ or less amniotic fluid. Exclusive detection of A antigen was successful from the mixed body fluids with $25 \%$ or more amniotic fluid (Fig. 8d, e).

\section{Discussion}

The forensic investigation in cases of criminal abortion and neonaticide necessitates careful scene examination and laboratory analysis to confirm the place of delivery. Detection of the amniotic fluid from the scene would provide the most positive information. Immunodetection of body fluid-specific proteins is widely accepted as a means to demonstrate the presence of corresponding body fluids. Some polyclonal antisera specific for semen (Tsuda et al. 1985), saliva (Eckersall et al. 1981), sweat (Tokiwa et al. 1987) and vaginal secretions (Itoh 1990) have been developed, and a few of them are used in practice. $A B H$ antigens of body fluids were expected to be distributed on particular proteins (Sagisaka 1989; Sagisaka et al. 1989, 1990), therefore monoclonal antibodies against the specific "carrier" proteins of saliva (Kimura et al. 1991a) and semen (Kimura et al. 1991b; Kishida et al. 1991) have been also prepared for blood grouping. We established a hybridoma clone excreting an IgG1 monoclonal antibody specific for the amniotic fluid. This antibody, namely ASP-1, did not react to human sera and proved to be useful for ABO blood grouping. Furthermore, ASP-1 did not cross-react with other human body fluids. The results of SDS-PAGE, immunoblotting and FPLC gel filtration indicated that the molecular weight of the amniotic protein carrying $\mathrm{ABO}$ blood group epitopes was identical with that of the ASP-1 reactive protein, but not with the proteins of other body fluids. It is therefore considered that ASP-1 would react exclusively with a unique amniotic protein possessing $\mathrm{ABH}$ blood group epitopes.

Some individual differences in the immunoreactivity against ASP-1 were demonstrated which correlated with the $\mathrm{ABH}$ blood group activity of the amniotic fluid. Diversity of secretor status of ABH blood group substances in the body fluids has been well established (Schiff and Sasaki 1932). This suggests that there could be a sort of secretor status for the amniotic blood group antigens. One specimen which did not react with ASP-1 or anti-A or -B, might be from an individual of the so-called non-secretor status, although it is more likely due to denaturation of an unknown cause.

Touchstone et al. (1972) reported that the amniotic fluid in the 17th week of pregnancy contained an average of $3.0 \mathrm{mg} / \mathrm{ml}$ of proteins and $60 \%$ was albumin. Because the fetus of this age is unable to synthesize the albumin, the presence in amniotic fluid must be of maternal origin. It has also been demonstrated that some amniotic serum types such as GC (Sutcliffe and Brock 1972), HP (Johnson 1974), and TF (Sutcliffe and Brock 1973) were identical with those of maternal serum. Although, the majority of the proteins in mid-trimester amniotic fluid proved to be of maternal serum origin, a small portion of the proteins originate 
from the fetus, and some have been shown to be specific for amniotic fluid (Jones and Spragg 1983). These include $\alpha$-uterine protein, $\alpha$-fetoprotein and fibronectin, and most have a molecular weight of 30-94 kDa (Jones and Spragg 1983; Marshall and Williams 1991). The amniotic protein recognized by ASP-1 must be from the fetus because it carries $\mathrm{ABH}$ group antigens (Ogita et al. 1975), and we are unaware that any amniotic fluid specific proteins with a molecular weight of more than $200 \mathrm{kDa}$ have been reported elsewhere. This protein should be presumably a glycoprotein, because it has high molecular weight and carries $\mathrm{ABH}$ blood group epitopes, although we failed to stain it with PAS reaction. The result of the present study might suggest that the protein contains relatively low amount of sugar, however, the nature of the protein still remains unclear. Detailed characterization of the protein should be performed in a prospective study.

The results of immunohistochemical staining implied that intermediate trophoblast of the placenta could produce the carrier protein. This protein was considered to be secreted just before delivery because both the full term placenta and amniotic fluid in the alveolar space of the neonate were stained with ASP-1. Although the full term amniotic fluid owes its blood group activity to antigens of various origin, it would contain amniotic fluid specific protein carrying $\mathrm{ABH}$ blood group epitopes.

ABO blood grouping of each constituent of mixed body fluid stains is one of the most challenging tasks for forensic serologists. Widespread use of ELISA has developed a new approach to this problem. Sagisaka et al. (1989) devised a double antibody sandwich ELISA using rabbit anti-human semen for exclusive capture of seminal ABH antigens. Human semen contains a few semen specific proteins (Hara et al. 1969; Tsuda and Hara 1988; Tsuda et al. 1988), and amongst them, Iki et al. (1988) demonstrated that $\alpha 2$-seminoglycoprotein ( $\alpha 2$-SGP) carries $\mathrm{ABH}$ antigens. A monoclonal antibody against $\alpha 2$-SGP produced by Kishida et al. (1991) should have facilitated discriminative blood grouping. In this study, the double antibody sandwich ELISA using ASP-1 as solid phase antibody was proved to be useful for $\mathrm{ABH}$ blood grouping of amniotic fluid from mixed body fluids. It was indicated that ASP-1 exclusively captured the carrier protein in the amniotic fluid and the ABH blood group of amniotic fluid could be detected and correctly typed. The $\mathrm{ABH}$ antigens of amniotic fluid could be detected when the mixed body fluid contained more than $20 \%$ of amniotic fluid. Even when it contained only $10 \%$, a comparison between the results of the sandwich ELISA and ELISA with solid phase antigen enabled us to estimate the blood group of amniotic fluid. In addition to the availability of discriminative blood grouping, the sandwich ELISA has another advantage. In the ELISA with solid phase antigen, competition among various proteins without blood group epitopes would possibly inhibit specific absorption of the carrier protein to the well surface, which should have caused failure of typing in the present study. Employment of the 
sandwich ELISA could remedy this problem. Although species specificity of ASP-1 could not be confirmed, it is less likely that it would be a matter of practical importance because the evidence samples are seldom contaminated by amniotic fluid of non-human origin. Thus, the sandwich ELISA with ASP-1 would be useful for forensic investigation.

\section{Acknowledǵment}

We wish to thank Dr. S. Uehara, Department of Obstetrics and Gynecology, Tohoku University School of Medicine, for providing the specimens.

\section{References}

1) Eckersall, P.D., Beeley, J.A., Dolton, P., Whitehead, P.H., Fletcher, S.M. \& Eynon, K. (1981) The production and evaluation of an antiserum for the detection of human saliva. J. Forensic Sci. Soc., 21, 293-300.

2) Hara, M., Inoue, T., Koyanagi, Y., Yamazaki, H., Fukuyama, T. \& Iki, H. (1969) Immunoelectrophoretic studies of the protein components in human seminal plasma (especially its specific component). Forensic immunological studies of body fluids and secretions. Report 6. Jpn. J. Legal Med., 23, 117-122. (in Japanese with English abstract)

3) Hsu, SM., Raine, L. \& Fanger, H. (1981) Use of avidin-biotin-peroxidase complex $(\mathrm{ABC})$ in immunoperoxidase techniques. A comparison between $\mathrm{ABC}$ and unlabeled antibody (PAP) procedures. J. Histochem. Cytochem., 29, 577-580.

4) Iki, H., Minamitake, H., Tsuda, R. \& Hara, M. (1988) Detection of ABO blood group of seminal stains mixed with vaginal secretion or blood by a method using NCF coated with anti $\alpha 2$-SGP serum. Forensic immunological studies of body fluids and secretions. Report 36. Jpn. J. Legal Med., 42, 504-508. (in Japanese with English abstract)

5) Itoh, Y. (1990) Analysis of human vaginal secretion using rabbit anti-human vaginal secretions: Detection of non-serum proteins. Jpn. J. Legal Med., 44, 267-271.

6) Johnson, A.M. (1974) Amniotic fluid proteins: Maternal and fetal contributions. $J$. Pediatr., 84, 588-593.

7) Jones, M.I. \& Spragg, S.P. (1983) Analysis of fetal peptides in human amniotic fluid and in fetal fluids and tissues by two-dimensional electrophoresis. Electrophoresis, $\mathbf{4}$, 291-297.

8) Kimura, A., Matsumura, F., Sodesaki, K. \& Tsuji, T. (1991a) Production and characterization of monoclonal antibodies against tissue specific epitopes on ABO blood group substances in saliva. Int. J. Leg. Med., 104, 193-196.

9) Kimura, A., Matsumura, F., Sodesaki, K., Osawa, M., Ikeda, H., Yasuda, S. \& Tsuji, T. (1991b) ABO blood grouping of semen from mixed body fluids with monoclonal antibody to tissue-specific epitopes on seminal $\mathrm{ABO}$ blood group substance. Int. J. Leg. Med., 104, 255-258.

10) Kishida, T., Tamaki, Y., Tsuda, R., Narahara, H., Katsumata, Y. \& Kimura, H. (1991) Production and characterization of a monoclonal antibody to ABH-carrying $\alpha 2$ seminoglycoprotein for ABO grouping of semen by ELISA. Int. J. Leg. Med., 104, 149-152.

11) Köhler, G. \& Milstein, C. (1975) Continuous cultures of fused cells secreting antibody of predefined specificity. Nature, 256, 459-497.

12) Laemmli, U.K. (1970) Cleavage of structural proteins during the assembly of the head of bacteriophage T4. Nature, 227, 680-685.

13) Marshall, T. \& Williams, K.M. (1991) The simplified technique of high resolution 
two-dimensional polyacrylamide gel electrophoresis: Biochemical applications in health and disease. Electrophoresis, 12, 461-471.

14) Ogita, S., Kawamura, T., Shimura, K., Ishiko, O., Noma, H., Onishi, M., Ando, T. \& Sugawa, T. (1975) A method for diagnosing $\mathrm{ABH}(\mathrm{O})$ blood group of the fetus. Osaka City Med. J., 23, 131-139.

15) Sagisaka, K. (1989) Some aspects of the ABH blood group from the standpoint of personal identification. Jpn. J. Legal Med., 43, 349-357. (in Japanese with English abstract)

16) Sagisaka, K. \& Takahashi, K. (1975) Identification of pregnancy from blood stains by anti-pregnancy associated globulin serum. Acta Crim. Jpn., 41, 245-249.

17) Sagisaka, K., Fletcher, S.M., Katsura, S. \& Yokoi, T. (1989) Specific capture of ABH blood group antigens of the red cell or body fluids by double antibody sandwich ELISA. Tohoku J. Exp. Med., 158, 211-219.

18) Sagisaka, K., Aoki, Y., Yokoi, T. \& Nata, M. (1990) On the protein carrying ABH epitopes in saliva and semen. Acta Crim. Jpn., 56, 189-193.

19) Schiff, F. \& Sasaki, H. (1932) Der Ausscheidungstypus., ein auf serologishen Wege nachweisbares Mendelndes Merkmal. Klin. Wschr., 11, 1426-1429.

20) Sutcliffe, R.G. \& Brock, D.J. (1972) Origin of amniotic fluid group-specific component. Nature, 238, 400.

21) Sutcliffe, R.G. \& Brock, D.J. (1973) Immunological studies on the nature and origin of the major proteins in amniotic fluid. J. Obstet. Gynecol. Br. Commonw., 80, 721727.

22) Tokiwa, K., Niitsu, H., Nakayashiki, N., Kumagai, R., Katsura, I. \& Katsura, S. (1987) Preparation of anti-human-sweat serum. Jpn. J. Legal Med., 41, 102-108. (in Japanese with English abstract)

23) Touchstone, J.C., Glazer, L.G., Bolognese, R.J. \& Litwin, S.D. (1972) Gestational age and amniotic fluid protein patterns. Am. J. Obstet. Gynecol., 114, 58-61.

24) Tsuda, R. \& Hara, M. (1988) Immunochemical studies on an iron-binding protein (seminoferrin) originating in the seminal vesicles. Forensic immunological studies of body fluids and secretions. Report 32. Jpn. J. Legal Med., 42, 21-27. (in Japanese with English abstract)

25) Tsuda, R., Iki, H., Kamachi, S. \& Hara, M. (1985) Demonstration of seminal stains by enzyme immunoassay using peroxidase-conjugated anti $\gamma$-seminoprotein $\mathrm{Fab}^{\prime}$. Forensic immunological studies of body fluids and secretion, report XXIV. Jpn. J. Legal Med., 39, 30-34 (in Japanese with English abstract).

26) Tsuda, R., Ito, Y. \& Hara, M. (1988) Immunochemical studies of a glycoprotein ( $\alpha 2$-seminoglycoprotein; $\alpha 2$-SGP) in seminal plasma. Forensic immunological studies of body fluids and secretions. Report 33. Jpn. J. Legal Med., 42, 28-37. (in Japanese with English abstract) 